\title{
Sığır veya Koyun ile Otlatılan Eskişehir Ovası Taban Meralarının Bitki Örtülerinin Karşılaştırılması
}

\author{
Ali KOÇ *Onur İLERI \\ Eskişehir Osmangazi Üniversitesi, Ziraat Fakültesi, Tarla Bitkileri Bölümü, Eskişehir \\ *Sorumlu yazar e-posta (Corresponding author e-mail): oileri@ogu.edu.tr
}

Öz

Eskişehir Ovasında 2014 yılında yürütülen bu çalışmada koyun ve sığır sürüleri ile otlatılan taban meraların bitki örtüleri ele alınmıştır. Mera kesimlerinde hakim türlerin çiçeklendiği dönemde halka yöntemi ile 40'ar hatlık ölçüm yapılmışır. Elde edilen verilerden yola çıkarak yapılan hesaplamalarda her iki mera kesiminde de köpek dişinin baskın tür olduğu, koyun otlatılan meralarda kofanın bulunmadığı, otlayan hayvan cinsine bağlı olarak mera bitki örtüsünde farklılıkların ortaya çıktı̆ı̆ıörülmüştür. Ele alınan meralarda bitki örtüsünün sık olmasına rağmen ağır otlatmadan dolayı tür bileşeninin olumsuz yönde değiştiği gözlenmiştir. Elde edilen sonuçlardan yola çıkarak Eskişehir ovasını temsilen ele alınan taban meralarının otlayan hayvan cinsine göre bitki örtülerinde farklılaşma olmakla birlikte ağır otlatmanın temel sorun olduğu ve bu meraların geliştirilmesi ve sürdürülebilir kullanımı açısından sürü tercihi, otlatma mevsimi ve otlatma kapasitesi ile ilgili yeni çalışmalara intiyaç olduğu sonucuna varıımıştır.

Anahtar Kelimeler: Taban mera, tür bileşeni, mera durumu ve sağlı̆ı, taşıma kapasitesi

\section{Comparison of Cattle and Sheep Grazed Sub-Irrigated Rangelands Vegetation in Eskişehir Plain}

\begin{abstract}
This research was carried out in Eskişehir Plain in 2014, to compare sub-irrigated rangelands vegetation of Eskişehir Plain which have been grazing by sheep and cattle. Measurements were made according to loop method with 40 transect for each rangeland sites in the period of dominant species flowering. In both rangeland sites, it was estimated that Bermuda grass was dominant, Common rush could be suppressed by sheep grazing and species composition was different at rangeland vegetation depend on grazing animal species. Although canopy was dense in investigated rangeland sites, species components were adversely affected from heavy grazing in both rangeland sites. It was concluded from the results that botanical composition of the sub-irrigated rangelands in Eskisehir Plain were shaped differently depending grazing animal type, heavy grazing is main problem and new studies on carried capacity, grazing season and animal type are needed to improve and sustainable use of these natural resources.
\end{abstract}

Keywords: Sub-irrigated rangeland, species component, rangeland condition and health, carrying capacity

\section{Giriş}

aban meralar yaz aylarında yeşil kalabilmeleri ve otlayan hayvanların içme suyu kaynaklarına veya yerleşim yerlerine yakın olmaları nedeniyle bozkır ekosistemlerinde mera hayvancılığında ayrıcalıklı bir yere sahiptir. Taban meralar gerçekte çayır bitki örtüsü formuna sahip olmakla birlikte yerleşim yerlerine yakın olması veya hayvanların uğrak yerlerine yakın olması nedeniyle otlatılarak değerlendirilmekte (Altın ve ark. 2011) ve ülkemizde resmi bir kayıt olmamakla birlikte mera varlığımız içerisinde hatırı sayılır bir yeri bulunmaktadır (Koç ve ark. 2014, 2015).

Ülkemizde taban meralar konusunda yapılan çalışma sınırlı olmakla birlikte orta malı taban meralarda ağır ve erken otlatmanın önemli bir sorun olduğu ve kofa (Juncus effisus) istilasının 
bu sorunlar içerisinde ilk sırlarda yer aldığına dikkat çekilmiştir (Koç ve ark. 2005; Sürmen ve Koç 2010). Ülkemizde taban meralardaki kofa yayılışında belirgin bir farklılık göze çarpmaktadır. Kofanın Orta Karadeniz bölgesinde manda, Doğu Anadolu bölgesinde ise koyun otlayan taban meralarda baskı altına alındığı yerel halk tarafından dile getirilmektedir. Nitekim Erzincan ili taban meralarında yapılan kişisel gözlemlerde (Koç 2010) koyun yetiştiriciliğinin yaygın olduğu köylere ait taban meralarda kofa bitkisinin sadece koyunların uğramadığı ender yerlerde koloni oluşturabildiğine rastlanılmıştır. Yerel halk ile yapılan görüşmelerden koyunların bu bitkiyi sonbahar dormant ve kış ölü dönemi ve ilkbahar gelişme başlangıcında otladığı anlaşılmıştır. Nitekim merada otlamaya elverişli yem azaldıkça hayvanların diğer bitkileri otlamaya yönelmeleri bilinen bir gerçektir (Holechek et al. 2004). Koyunlar ağız anatomilerindeki farklılık nedeniyle sığırlara göre daha seçici otlayabilme yeteneğine sahiptirler ve özellikle yemin kıt olduğu alanlarda karınlarını doyurabilen kanaatkar hayvanlardır (Altın ve ark. 2011) ve Bakır (1987)'ın bildirdiğine göre çiftlik hayvanları içerisinde en fazla bitki türü otlayabilme özelliğine sahiptirler. Bu yönü ile koyunlar otsu yabancı bitkiler ile biyolojik mücadelede etkili olabilecek bir özellik sergilemektedir. Nitekim Ardahan'da yürütülen bir çalışmada (Dumlu 2010) koyun ve sığırın birlikte otlatıldığı meralarda sadece sığır otlatılan meralara göre Alchemilla caucasica bitkisinin yayılışının azaldığı kaydedilmiş ve bu azalışta koyunların etkin olduğuna dikkat çekilmiştir. İngiltere'de yapılan çalışmalarda (Merchant 1993) kofa bitkisinin koyuna benzer bir ağız anatomisine sahip olan keçiler tarafından kontrol edilebildiğini ve bu bitkinin erken ilkbaharda otlatmaya hassas olduğuna dikkat çekilmiştir.

Ülkemiz taban meralarında kofa istilası yaygın bir sorun olmakla birlikte otlayan hayvanların bu konudaki rolü üzerinde fazla durulmamıştır. Bu çalışma benzer arazi yapısına sahip taban meralarda kofanın sorun olmadığı ve sorun olduğu iki farklı mera kesimindeki çevre faktörlerinin kofanın yayılışındaki rolünü ortaya koymak amacıyla planlanmıştır.

\section{Materyal ve Yöntem}

Bu çalışma Eskişehir ovasında benzer saha yapısına sahip iki taban mera kesiminde 2014 yılında yürütülmüştür. Eskişehir ovasına uzun yıllar ortalamasına göre $338.8 \mathrm{~mm}$ yağış düşmekte ve yıllık ortalama sıcaklık $10.7^{\circ} \mathrm{C}$ civarında seyretmektedir. Araştırmanın yürütüldüğü yılda ise $358.0 \mathrm{~mm}$ yağış düşmüş ve yıllık ortalama sıcaklık ise $12.1^{\circ} \mathrm{C}$ olarak gerçekleşmiştir. Ele alınan mera kesimlerinden Muttalip Köyü merası 780 m rakımda (3949'56" $\left.\mathrm{N}, 30^{\circ} 33^{\prime} 10^{\prime \prime} \mathrm{E}\right)$ ve düz bir topografyaya sahiptir. Köy merası koyun sürüleri ile otlatılmakta ve kar kapatmadığı sürece merada otlatma devam etmektedir. Mera toprakları killi bünyeye sahip olup hafif alkalin ( $\mathrm{pH}: 7.7)$, organik madde yönünden zengin (\%16), kireç yönünden yeterli, fosfor yönünden fazla ve potasyum yönünden zengindir. Yahnikapan Köyü merası 800 m rakımlı (39³8'39" N, 3047'34" E) ve düz bir topografyaya sahiptir. Köy merası sığır sürüleri ile otlatılmakta ve ilkbaharda otlar sığır otlayabilecek boya ulaşınca otlatma başlatılmakta ve sonbaharda havalar bozuncaya kadar devam etmektedir. Mera toprakları killi-tın bünyeye sahip olup hafif alkalin ( $\mathrm{pH}: 7.7)$, organik madde yönünden zengin (\%15), kireç yönünden yeterli, fosfor yönünden yeterli ve potasyum yönünden zengindir. Haziran ayının ikinci yarısında baskın türler çiçeklendiği dönemde her bir mera kesiminde detayları Altın ve ark. (2011) tarafından izah edilen her biri 100 noktadan oluşan halka yöntemi ile 40 hatlık ölçüm yapılmıştır. Elde edilen sonuçlardan yola çıkarak Altın ve ark. (2011)'ın belirttiği esaslara göre bitki örtüsünün toprağı kaplama oranı, tür bileşeni, mera durumu ve sağlığı, taşıma kapasitesi hesaplanmıştır. Yine Anonim (2008)'den faydalanarak türlerin otlatmaya tepkileri belirlenmiştir. Bitki örtülerindeki farklıığı ortaya koymak için elde edilen verilere CANOCO versiyon 4.5 (Ter Braak and Smilauer 2002) bilgisayar programı kullanılarak dolaylı gradinet analiz ile unimodel metot olan Canonical analiz (CA) yöntemi ile ordinasyon analizi uygulanmıştır.

\section{Bulguları ve Tartışma}

Koyun sürüleri ile otlatılan Muttalip köyü meralarında 3'ü azalıcı, 2'si çoğalıcı ve 12'si istilacı olmak üzere toplam 17 tür kaydedilirken, sığır sürüleri ile otlatılan Yahnikapan köyü meralarında ise 2'si azalıcı, 2'si çoğalıcı ve 17'si istilacı olmak üzere toplam 21 bitki türü kaydedilmiştir (Çizelge 1). Her iki mera kesiminde de baskın tür köpek dişi (Cynodon dactylon) olmuştur. Kofa (Juncus effusus) bitkisi sığır ile otlatılan merada \%34.43 oranında tür bileşenine iştirak ederken, koyun ile otlatılan 
merada bu türe rastlanılamamıştır. Koyun ile otlatılan meranın tür bileşeninde kayda değer bir paya (\%14.01) sahip olan pisipisi arpası (Hordeum murinum)'na sığır ile otlatılan merada eseri oranda $(\% 0.50)$ rastlanılması dikkat çekici olmuştur. Morfolojik olarak buğdaygillere benzeyen Carex spp. türlerinin koyun otlayan merada yüksek oranda bulunması dikkat çeken bir diğer konu olmuştur. Ele alınan meralarda bitki örtüsünün toprağı kaplama oranı \%80'in üzerinde olmuş ve bu yönden meralar arasında belirgin bir farklııık göze çarpmamıştır. Meralar her iki kesimde de sağlıklı sağlık sınıfında yer alırken, mera durum puanı koyun otlatılan merada 29.41, sığır otlatılan merada ise 19.04 olarak hesaplanmıştır (Çizelge 1). Buna göre koyun otlatılan mera kesimi orta, sığır otlatılan mera kesimi ise zayıf mera durum sınıfında yer almıştır. Sağlık ve durum sınıfı bir arada değerlendirildiğinde koyun otlatılan mera kesimi sağlıklı-orta, sığır otlatılan mera kesimi ise zayıforta sınıfta yer almıştır. Bu sonuçlara göre 6 aylık otlatma döneminde bir hayvan ünitesi için Muttalip köyü merasında 6.8 hektar, Yahnikapan köyü merasında ise 12 hektar alana intiyaç olduğu hesaplanmıştır.

Dolaylı gradient analizi esasına göre Canonical analiz yöntemi ile yapılan ordinasyon analizinde türlerin eksenlere göre değişkenliği $\% 38.3,10.9,10.2$ ve 8.7 ve eklemeli oransal varyans sırasıyla $29.1,37.4,45.1$ ve 51.7 olarak hesaplanmıştır. Analiz sonuçlarının sunulduğu şekil 1 incelendiğinde eksenin sağında sığır otlatılan merada rastlanılan bitki türlerinin, solunda ise koyun otlatılan merada rastlanılan bitki türlerinin küme oluşturduğu gözlenmektedir. Yaygın türlerden köpek dişi orta eksene yakın bir yerde yer almakta olup bu türün her iki mera kesiminde de yaygın olduğu, dolayısıyla mera kesimleri arasında yayılış yönünden ciddi bir farklıık sergilemediği anlaşılmaktadır. Bir başka ifadeyle otlayan hayvan cinsinin bu türün dağılışı üzerine ciddi bir etkisinin olmadığını söylemek mümkündür. Diğer yandan tek yıllık buğdaygiller ve Carex spp. türlerinin koyun otlatılan meradaki bitki kümesinin merkeze uzak bölümünde, kofa, adaçayı ve otlak ayrığı gibi türlerin de sığır otlatılan meralardaki bitki kümesinin merkeze uzak bölümünde yer aldığı görülmektedir. Bu sonuçlar benzer saha özelliklerine sahip meralarda farklı hayvan cinsleri ile farklı otlatma mevsimi uygulamalarının bitki örtüsünde belirgin bir farklılığa yol açtığı şeklinde yorumlanabilir.
Ele alınan mera kesimlerinin bitki örtüsünün tür bileşeni ile ilgili göze çarpan en önemli özellik koyun otlatılan meralarda kofa bitkisinin olmayışı ve buna karşııı tek yıllık buğdaygiller ve Carex spp. oranının yüksek olması ve her iki mera kesiminde de köpek dişinin baskın tür olmasıdır. Bu durumun otlayan hayvanların yem tercihi, otlatma yoğunluğu ve otlatma mevsimi ile ilgili olması muhtemeldir. Zira ülkemizdeki geleneksel koyun yetiştiriciliğinde hayvanların meraya ulaşımında (kar örtüsü, su baskını vb) sorun olmadığı sürece sürüler merada otlatılmaktadır (Koç 2006). Bu durum özellikle merada yemin kıt olduğu sonbahar ve ilkbahar yeniden sürümün başladığı dönemde koyunların yoğun olarak kofa otlamasına sebep olmaktadır. ìlkbaharda ortaya çıkan kofa sürgünlerinin küçükbaşlar için lezzetli olması ve bu dönemde otlatmaya karşı dayanıkı olmaması (Merchant 1993) ve bu otlatma yönetiminin uzun yıllardan beri devam etmesi koyun otlatılan meralarda kofaların yok olmasında etkili olmuştur. Köpek dişinin yaygın olmasında ise hem bitkinin rizom hem de stolon ile çoğalabilmesi hem de su baskını ve çiğnemeye dayanıklı olması yatık geliştiği için otlatmaya da dayanıklı olmasının etkili olması muhtemeldir (Burton and Hanna 1995). Taban meralarda çiğneme ve ağır otlatmanın temel sorun olduğu göz önüne alındığında bu bitkinin her iki kesimde de yaygın olması beklenen bir sonuçtur. Sığırlar otlarken otu dilleriyle kavrayıp çekmek suretiyle kopardıkları için (Altın ve ark. 2011) tek yıllık bitkileri kökleriyle birlikte yolmaktadır. Bu durum sığır otlayan meralarda tek yıllık buğdaygillerin az olmasının temel nedeni olmalıdır. İncelenen meralarda bitki örtüsünün sıklığı arazinin nem bilançosunun pozitif olması ile ilgili bir durumdur. Çünkü meralarda nemlilik arttıkça bitki örtüsünün sıklığı da artmaktadır (Koç 1995). Artan sıklık mera sağık sınıfının sağlıklı olmasının temel nedeni olurken (Altın ve ark. 2011), ağır otlatmaya bağlı olarak meralarda yabancı otların oranının artmasının bir sonucu olarak mera durum sınıfının azalmasına sebep olmuştur. Zira dünyada ağır otlatmanın olumsuzluğunu telafi edecek bir otlatma sistemi mevcut değildir (Holechek et al. 2004). Sığır otlatılan meralarda koyun otlatılan meralara göre mera durum sınıfının daha da düşük olması ise bitki örtüsünde kofa yoğunluğunun fazla olmasının bir sonucudur. Zira kofa meralar için istilacı bitki sınıfındadır (Anonim 2008). 
Koç ve İleri "Sığır veya Koyun ile Otlatılan Eskişehir Ovası Taban Meralarının Bitki Örtülerinin Karşılaştırılması"

Çizelge 1. Ele alınan mera kesimlerinin bitki örtülerinin bazı özellikleri

Table 1. Vegetation of studied rangeland sites

\begin{tabular}{|c|c|c|c|}
\hline \multirow{2}{*}{ Bitki Grupları } & \multicolumn{2}{|r|}{ Muttalip Merası } & Yahnikapan Merası \\
\hline & & Oran \% & Oran \% \\
\hline \multicolumn{4}{|l|}{ Buğdaygiller } \\
\hline Agropyron cristatum & A & 0 & 1.07 \\
\hline Agropyron intermedium & A & 0.03 & 0.24 \\
\hline Bromus tectorum & i & 1.61 & 0.03 \\
\hline Cynodon dactylon & Ç & 48.75 & 43.15 \\
\hline Festuca ovina & $\mathrm{C}^{3}$ & 3.88 & 7.31 \\
\hline Hordeum murinum & 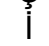 & 14.01 & 0.50 \\
\hline Lolium perenne & A & 0.52 & 0 \\
\hline Toplam & & 68.8 & 51.85 \\
\hline \multicolumn{4}{|l|}{ Baklagiller } \\
\hline Astragalus sp. & i & 2.47 & 1.25 \\
\hline Medicago minima & i & 2.41 & 0.18 \\
\hline Medicago polymorpha & i & 0.86 & 0 \\
\hline Trifolium repens & A & 0.06 & 0 \\
\hline Toplam & & 5.80 & 1.43 \\
\hline \multicolumn{4}{|l|}{ Ekşi Çayır Otları } \\
\hline Carex sp. & i & 17.92 & 5.32 \\
\hline Juncus effusus & i & 0 & 34.43 \\
\hline Toplam & & 17.92 & 39.75 \\
\hline \multicolumn{4}{|l|}{ Diğer Familyalar } \\
\hline Centaurea sp. & i & 0.46 & 0.15 \\
\hline Chenepodium album & i & 2.58 & 0.83 \\
\hline Convolvulus arvensis & i & 1.00 & 3.18 \\
\hline Delphinium & i & 0 & 0.18 \\
\hline cyphoplectrum & $\mathrm{i}$ & 0 & 1.49 \\
\hline Galium verum & i & 2.27 & 0.06 \\
\hline Minuartia anatolica & i & 0.29 & 0.06 \\
\hline Plantago lagopus & i & 0 & 0.27 \\
\hline Potentilla argentea & i & 0 & 0.24 \\
\hline Salvia sp. & $\mathrm{i}$ & 0.89 & 0.06 \\
\hline $\begin{array}{l}\text { Taraxacum sp. } \\
\text { Toplam }\end{array}$ & & 7.49 & 6.52 \\
\hline \multicolumn{4}{|l|}{ Tercih durumu } \\
\hline Azalıcı Tür Sayısı & & 17.65 & 9.52 \\
\hline Çoğalıcı Tür Sayısı & & 11.76 & 9.52 \\
\hline İstilacı Tür Sayısı & & 70.59 & 80.96 \\
\hline Baskın Tür & & Cynodon dactylon (48.75\%) & Cynodon dactylon (43.15\%) \\
\hline Kaplılık Oranı (\%) & & 87.08 & 84.08 \\
\hline Mera Durumu & & Orta $(\% 29.41)$ & Zayıf (\%19.04) \\
\hline Mera Sağlık Sınıfı & & Sağlıklı & Sağlıklı \\
\hline Taşıma Kapasitesi $(\mathrm{HOH})(\mathrm{ha})$ & & 6.8 & 12 \\
\hline
\end{tabular}

$\mathrm{A}=$ Azalıcı, Ç= Çoğalıcı, İ= İstilacı

$A=$ Decreasers, $C=$ Increasers, $\dot{l}=$ Invaders

Meraların taşıma kapasitesi mera durum ve sağlık sınıfı ile doğrudan ilişkili olduğu (Aıtın ve ark. 2011) için durum sınıfının zayıf olduğu sığır otlatılan merada bir hayvan ünitesi için otlatma mevsiminde ayrılması gereken alanın daha yüksek olarak hesaplanmış olması beklenen bir durumdur. Benzer saha yapısına sahip meralarda bitki örtüsünün farklılaşmasında otlayan hayvan cinsi ve uygulanan otlatma mevsiminin etkili olması beklenen bir durumdur. Ele alınan iki mera kesimi de benzer alan yapısına sahip olmasına rağmen bitki örtülerinin 


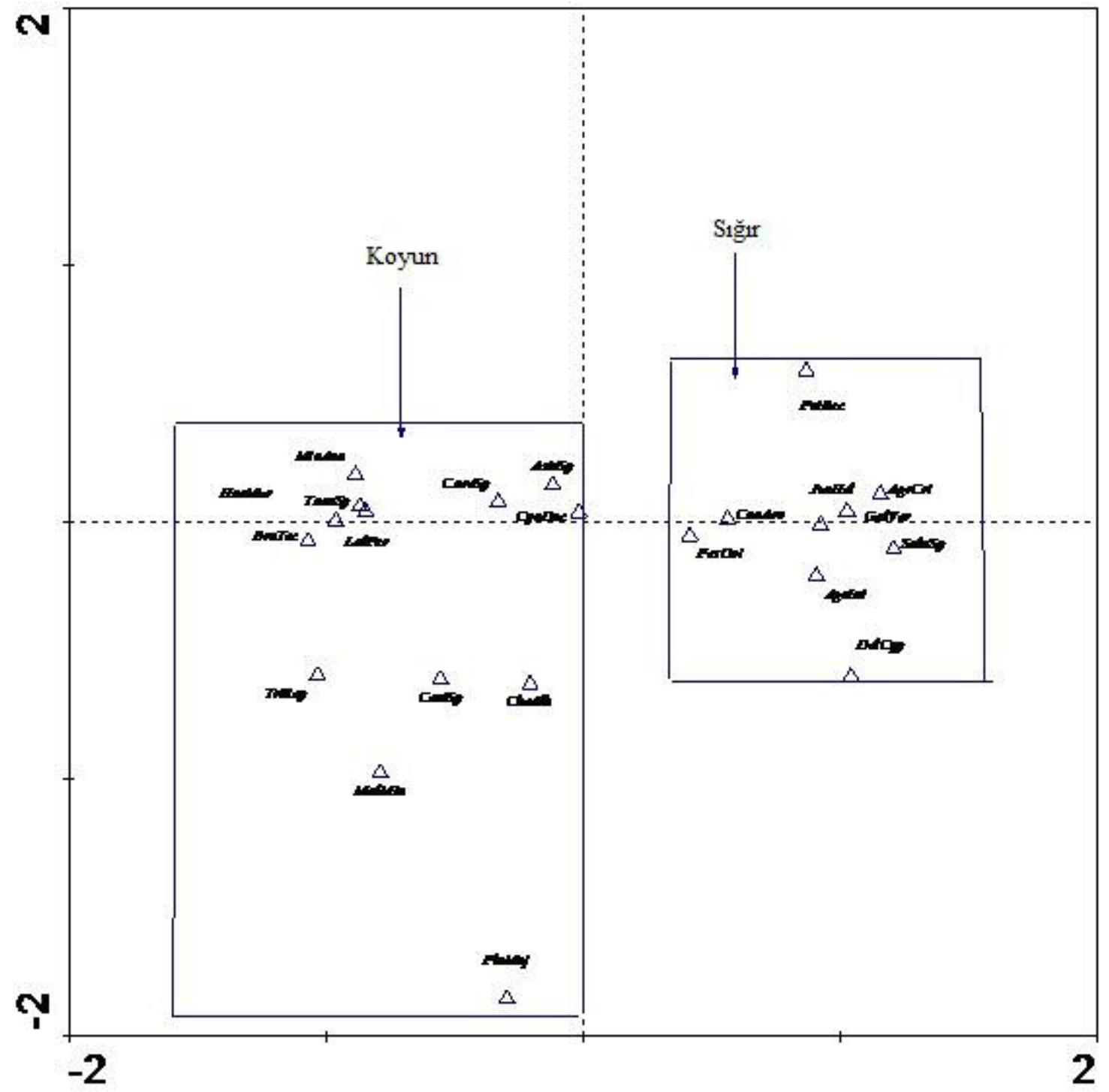

Şekil 1. Ele alınan mera kesimlerinin verilerine ait ordinasyon analizi sonuçları

Figure 1. Ordinasion analysis results of studied rangeland sites

farklı kümeleşmesinde otlayan hayvan cinsleri etkili olmuştur. Nitekim merada otlayan hayvan cinslerinin mera bitki örtüsünün şekillenmesinde etkili olduğu Holechek et al. (2004) ve Arevalo et al. (2011) tarafından da dile getirilmiştir. Ordinasyon analizi sonuçları irdelendiğinde meraların tek tip hayvan ile otlatılması yerine büyükbaş ve küçükbaş hayvanlar ile karışık otlatılmasının bitki örtüsünün bileşenini olumlu yönde etkileyebileceğini söylememiz mümkündür. Ancak otlatma yoğunluğuna dikkat edilmedikçe bu şekildeki bir otlatma tercihinin faydalı olması beklenemez.

\section{Sonuç}

Bitki örtüsünün tür bileşeni ile ilgili özellikler bir bütün olarak değerlendirildiğinde ele alınan mera kesimlerinde ağır otlatma temel sorundur. Çünkü mera durum sınıfı bunun en iyi göstergesidir. Elde edilen sonuçlara göre Eskişehir ovası taban meralarında sığır otlatılan meralarda kofa ve köpek dişindeki yoğunluğun artması, koyun otlatılan meralarda ise köpek dişi ve tek yıllık buğdaygillerin yoğunluğunun artması ağır otlatmanın göstergesidir. Eskişehir ovasında taban meralarda kofa istilası ile mücadelede geç sonbahar ve erken ilkbahar 
koyun otlatması etkili bir araç olabilir. Diğer yandan kofa istilasının en önemli nedeni çiğneme olarak düşünülecek olursa (Koç ve ark. 2005) bu meralarda otlatma mevsimi (özellik,le ilkbaharda otlatmaya başlama zamanı), otlatma yoğunluğu, uygulanacak otlatma sistemi ve sürü tercihlerinin ortaya konulmasının yanı sıra mevcut bitki örtülerinin ıslahı konusunda çalışmalara intiyaç vardır.

\section{Kaynaklar}

Altın M., Gökkuş A. ve Koç A., 2011. Çayır ve Mera Yönetimi. Tarım ve Köyişleri Bakanlığı Tarımsal Üretim ve Geliştirme Genel Müdürlüğü Yayınları, 1. Cilt. Ankara

Anonim, 2008. Türkiye'nin Çayır ve Mera Bitkileri. Tarım ve Köyişleri Bakanlığı Tarımsal Üretim ve Geliştirme Genel Müdürlüğü Yayınları, Ankara

Arevalo J.R., de Nascimento L., Fernandez-Lugo S., Mata J. and Bermejo L., 2011. Grazing effects on species composition in different vegetation types (La Palma, Canary Islands). Acta Oecologica, 37: 230-238

Bakır Ö., 1987. Çayır-Mer’a Amenajmanı: Ankara Üniversitesi Ziraat Fakültesi Yayınları 992, Ders Kitabı (292-362), Ankara

Burton G.W. and Hanna W.W., 1995. Bermudagrass, (Eds: R.F. Barnes, D.A. Miller and C.J. Nelson), Forages, An Introduction to Grassland Agriculture. Vol. I, lowa State Univ. Press, lowa, p. 421-430

Dumlu S.E., 2010. Ardahan ili meralarının uzaktan algılama ve coğrafi bilgi sistemi teknikleri ile sınıflandırılması. Yüksek Lisans Tezi, Atatürk Üniversitesi, Fen Bilimleri Enstitüsü, s. 75.

Holechek J.L., Pieper R.D. and Herbel C.H., 2004. Range Management Principles and Practices. Pearson Education, Inc, New Jersey
Koç A., 1995. Topografya ile toprak nem ve sıcaklığının mera bitki örtülerinin bazı özelliklerine etkileri. Doktora Tezi, Atatürk Üni. Fen Bil. Enst., Tarla Bitk. Anabilim Dalı, Erzurum

Koç A., 2006. Rangeland types and traditional management practices in Turkey. Proc. $5^{\text {th }}$ Panhellenic Rangel. Cong., Iraclion, Crete, Greece, Nov.1-3, 2006. p.199-206

Koç A., 2010. Erzincan ili mera ıslah çalışmaları arazi etüdü gözlemleri (Kişisel gözlemler)

Koç A., Kaya A., Güllap M.K., Erkovan H.I.., Macit M. and Karaoğlu M., 2014. The effect of supplemental concentrate feed on live weight gain of yearling heifers overgrazing season in subirrigated rangelands of East Anatolia. Turkish J. Vet. Anim. Sci., 38: 278-284

Koç A., Schacht W.H. and Erkovan H.I., 2015. The history and current direction of rangeland management in Turkey. Rangelands, 37:3946

Koç A., Sürmen M. and Kaçan K., 2005. Erzincan ovası taban meralarının bitki örülerinin mevcut durumu. Türkiye VI. Tarla Bitkileri Kongresi, 5-9 Eylül, Antalya, Bildiri Kitabı Cilt II: $847-850$

Merchant M., 1993. The potential for control of the soft rush (Juncus effusus) in grass pasture by grazing goats. Grass and Forage Science, 48: 395-409

Sürmen M. ve Koç A., 2010. Orta Karadeniz Bölgesinde kofa (Juncus effusus L.) istilasına uğrayan taban meralar için uygun Islah yöntemlerinin belirlenmesi. Türkiye IX. Tarla Bitkileri Kongresi, 12-15 Eylül, Bursa, III: 1767-1772

Ter Braak C.J.F. and Smilauer P., 2002. CANOCO Reference Manual and CanoDraw for Windows User's Guide: Software for Canonical Community Ordination (version 4.5). Microcomputer Power, Ithaca, New York 